\title{
APLICAÇÕES DA TEORIA TRANSCULTURAL NA PRÁTICA DA ENFERMAGEM A PARTIR DE DISSERTAÇÕES DE MESTRADO
}

\author{
Marisa Monticelli ${ }^{1}$, Astrid Eggert Boehs ${ }^{2}$, Joice Cristina Guesser ${ }^{3}$, Taise Gehrmann ${ }^{4}$, Marialda Martins ${ }^{5}$, \\ Gisele Cristina Manfrini ${ }^{6}$
}

\footnotetext{
${ }^{1}$ Doutora em Enfermagem. Professora Associado do Programa de Pós-Graduação em Enfermagem (PEN) da Universidade Federal de Santa Catarina (UFSC). Santa Catarina, Brasil. E-mail: marisa@nfr.ufsc.br

${ }^{2}$ Doutora em Enfermagem. Professora Associado do PEN/UFSC. Santa Catarina, Brasil. E-mail: astridboehs@hotmail.com

${ }^{3}$ Especialista em Saúde Pública. Enfermeira do Serviço de Emergência Adulto do Hospital Universitário da UFSC. Santa Catarina, Brasil. Email: joiceguesser@yahoo.com.br

${ }^{4}$ Especialista em Saúde da Família. Enfermeira da Prefeitura Municipal de Guaramirim. Santa Catarina, Brasil. E-mail: taisegehrmann@gmail.com

${ }^{5}$ Doutoranda do PEN/UFSC. Docente do Departamento de Enfermagem da Universidade Federal do Paraná. Paraná, Brasil. E-mail: marialda@ufpr.br

${ }^{6}$ Doutoranda do PEN/UFSC. Bolsista CNPq. Santa Catarina, Brasil E-mail: gisamanfrini@yahoo.com.br
}

RESUMO: Pesquisa bibliográfica que objetivou analisar a operacionalização da metodologia assistencial em dissertações de enfermagem elaboradas com base na Teoria de Enfermagem Transcultural. Foram avaliadas 26 dissertações defendidas em um Programa de PósGraduação, entre 1990 e 2005. A partir de um roteiro-guia foi realizada a análise de conteúdo, envolvendo convergências e divergências entre os dados coletados, tendo por base interpretativa a própria teoria. Os resultados mostraram que os mestrandos optaram por propostas metodológicas flexíveis e criativas. A fase de avaliação culturológica e implementação dos cuidados contempla grande profusão de instrumentos e técnicas. Há lacunas no que diz respeito ao próprio significado do termo "cultura". Além disso, muitos desses estudos são omissos no que se refere à etapa assistencial da operacionalização das ações planejadas. Conclui-se que, tanto os pontos positivos, quanto as fragilidades apresentadas nos resultados desses trabalhos, contribuem para que as enfermeiras possam realizar o cuidado culturalmente congruente, em qualquer cenário assistencial.

DESCRITORES: Enfermagem transcultural. Teoria de enfermagem. Pesquisa em enfermagem. Metodologia.

\section{TRANSCULTURAL THEORY APPLICATIONS IN NURSING PRACTICE FROM MASTER'S THESES}

\begin{abstract}
This bibliographic research aimed to analyze the nursing care operational methodology in nursing dissertations prepared based on the Theory of Transcultural Nursing. We evaluated 26 theses defended in a Nursing Graduate Program in Brazil from 1990 to 2005. From a script guide content analysis was performed, involving similarities and differences between the data collected, using the theory itself as the basis for interpretation. The results showed that masters' students chose flexible and creative methodological proposals. The process of a cultural study evaluation and care implementation includes a large variety of tools and techniques. There are shortcomings with regard to the meaning of the term "culture". Moreover, many such studies are lacking regarding to the care stage step of making planned actions operational. We concluded that as much the positive points as the fragilities presented in the results of these studies contribute so that nurses may perform culturally congruent care in any care setting.
\end{abstract}

DESCRIPTORS: Transcultural nursing. Nursing theory. Nursing research. Methodology.

\section{APLICACIONES DE LA TEORIA TRANSCULTURAL EN LA PRÁCTICA DE ENFERMERÍA A PARTIR DE TESIS DE MAESTRÍA}

RESUMEN: Es una investigación bibliográfica que tuvo como objetivo analizar la operacionalización de la metodología asistencial en tesis de Enfermería elaboradas en base a la Teoria de la Enfermería Transcultural. Se evaluaron veintiséis tesis de maestría defendidas en un Programa de Postgrado, de 1990 hasta 2005. El análisis de contenido se hizo a través de un guión, donde se consideraron las convergencias y divergencias entre los datos recolectados, basado en la propia teoría. Los resultados muestran que los estudiantes de maestría optaron por propuestas metodológicas flexibles y creativas. La fase de evaluación de la cultura e de implementación del cuidado ofrece una gran cantidad de herramientas y técnicas. Existen vacíos en lo que se refiere al verdadero significado del término "cultura". Además, muchos de esos estudios presentan omisión en lo que respecta a la etapa asistencial de la operacionalización de las acciones previstas. Se concluye que tanto los puntos positivos, como las debilidades presentadas en los resultados de este estudio contribuyen para que las enfermeras puedan llevar a cabo un cuidado culturalmente congruente en cualquier local asistencial.

DESCRIPTORES: Enfermería transcultural. Teoría de enfermería. Investigación en enfermería. Metodología. 


\section{INTRODUÇÃO}

Desde Florence Nightingale estão sendo realizados esforços para que a enfermagem se fortaleça como profissão e como disciplina, ou seja, que tenha um corpo de conhecimentos organizado e competente, com a finalidade de dar sustentação à prática, ao ensino e à pesquisa. Um dos caminhos empreendidos nessa direção tem sido a formulação de teorias, principalmente durante o século passado e no transcorrer do atual, sempre em interlocução com outras disciplinas e áreas de saber. ${ }^{1}$

Tal conhecimento, na maioria das vezes, engloba também um modo de fazer ou sugere metodologias que viabilizam a operacionalização dessas teorias, em diferentes contextos e cenários investigativos, educativos ou assistenciais, com forte vinculação a este último, já que, no processo de cuidar em enfermagem, teoria e prática devem se alimentar em mútua constância. Este é um dos fatores que permite, inclusive, a possibilidade de refutação ou de continuação da aceitabilidade da(s) própria(s) teoria(s). ${ }^{2}$

Mais recentemente, esforços têm sido empreendidos em vários países, e também no Brasil, para implantar a sistematização da assistência, nos diferentes níveis de atenção em que a enfermagem atua. ${ }^{3-5}$ Se compreendermos este processo como um modo de organizar o exercício do cuidado profissional, estaremos, em última instância, diante de estratégias de operacionalização de referenciais teóricos, estejam eles implícitos ou explícitos.

No que diz respeito à dimensão cultural do cuidado de enfermagem, podemos afirmar que, há mais de 50 anos, a profissão tem se preocupado com as diferenças existentes entre as enfermeiras exercendo seu cuidado profissional e os cuidados requeridos pelos clientes. Neste contexto, a teoria da enfermeira americana Madeleine Leininger, denominada Teoria da Diversidade e Universalidade do Cuidado Cultural, surgiu e tem se mantido ainda como uma proposta para compreender estas diferenças. ${ }^{6-8}$ Esta teórica argumenta que o conceito de cultura e o conceito de cuidado devem ser focados na prática e na pesquisa de enfermagem. Enfatiza, também, que é necessário reconhecer a existência do sistema de cuidado profissional, mas, igualmente, do sistema de cuidado popular. Apresenta uma metodologia, na qual a enfermeira, ao interagir com os clientes, em variadas situações assistenciais, deve utilizar ações profissionais, de forma a preservar, negociar ou repadronizar os cuidados, buscando a congruência cultural. ${ }^{6-7} \mathrm{~A}$ metodologia proposta pela autora, no seu Modelo do Sol Nascente, é apresentada de forma ampla, tendo por base o método etnográfico. Contudo, a teórica estimula que os enfermeiros utilizem a criatividade para executar tal método e, também, a necessidade de exercitar o olhar destituído de preconceitos profissionais.

Este referencial teórico-metodológico tem sido utilizado há aproximadamente trinta anos no Brasil, como fundamentação para a prática assistencial. Contudo, a análise de seu emprego tem sido pouco frequente. Produções mais amplas, envolvendo estudos de meta-análise ou de adequações e interpretações críticas de seu uso, na prática profissional, têm sido publicadas, ${ }^{9-12}$ mas não com a regularidade requerida. Um estudo recente, que identificou o perfil de trabalhos acadêmicos realizados, tendo por base a teoria de Leninger, mostrou que houve produção significativa de dissertações, oriundas do Programa de Pós-Graduação em Enfermagem (PEN) da Universidade Federal de Santa Catarina (UFSC), utilizando esta teoria, com grande concentração entre os anos de 1990 e 2005..$^{13}$ Neste estudo, as autoras referem que tais dissertações envolvem assuntos e tipologias que são considerados raros nas publicações nacionais e internacionais, uma vez que se tratam de propostas de desenvolvimentos, implementações e avaliações de práticas assistenciais (ou seja, metodologias), balizadas no referencial de Leininger. Isto se deve ao fato de que, a partir de 1990, o PEN/UFSC introduziu a modalidade de dissertações de mestrado contemplando a operacionalização (aplicação prática) de teorias de enfermagem. Esta modalidade de estudo foi posteriormente evoluindo para a Pesquisa Convergente-Assistencial, ${ }^{14}$ uma modalidade de pesquisa de campo que utiliza como fontes de inspiração a pesquisa-ação e o processo de enfermagem.

O presente estudo, em consonância com os resultados publicados anteriormente, ${ }^{13}$ tem por objetivo analisar a operacionalização da metodologia assistencial nas dissertações de enfermagem elaboradas com base na Teoria de Leininger.

\section{METODOLOGIA}

Trata-se de pesquisa bibliográfica que utilizou como fonte de obtenção de dados as 26 dissertações de mestrado defendidas no contexto do PEN/UFSC, durante o período de 1990 a 2005, e que tiveram como referencial a Teoria da Diversidade e Universalidade do Cuidado Cultural. Estas 
obras foram intencionalmente selecionadas por se constituírem em relatos de experiência de prática assistencial ou em investigações auto-declaradas como Pesquisas Convergente-Assistenciais (PCAs). ${ }^{14} \mathrm{O}$ período da amostra foi assim delimitado pelo fato de que estas modalidades de dissertações iniciaram em 1990 e a coleta de dados da presente pesquisa iniciou no ano de 2006. Foram excluídas, entretanto, aquelas dissertações que não explicitavam a metodologia adotada ou que a registravam de modo impreciso, ou ainda, de difícil compreensão. Após o filtro de exclusão, cinco dissertações foram retiradas da amostra, resultando então num corpus final de 21 dissertações.

Para a obtenção dos dados foi montado um esquema-guia contendo dois amplos tópicos. $\mathrm{O}$ primeiro relacionava-se à definição que o(a) mestrando(a) atribuía ao conceito Metodologia Assistencial (ou termo similar), bem como o período de implementação desta metodologia na prática assistencial, independente da população que estava sob assistência. O segundo tópico versava sobre as etapas componentes da Metodologia Assistencial. Independente dos termos utilizados pelo(a) mestrando(a) para se referir a estas etapas, o esquema analítico considerou as fases tradicionais do método científico. Assim, essa parte do esquema-guia se desdobrava em: a) etapa de coleta dos dados (Qual a finalidade da mesma? Quais técnicas ou guias habilitadores foram usados? Qual o conteúdo das informações ou o tipo de dados levantados?); b) etapa de diagnóstico (Em que consiste? Qual o modo de operacionalização e de registro?); c) etapa de planejamento dos cuidados e fase de implementação dos cuidados (Qual a forma e o conteúdo que o autor utiliza para operacionalizar o plano de cuidados? Quais os modos de cuidar utilizados: manter, negociar, repadronizar? Qual o significado de cada um dos modos e a tipologia de ações planejadas em cada um desses modos?); d) etapa de avaliação dos cuidados implementados (Qual a forma e o conteúdo utilizado para analisar se os cuidados são congruentes ou não com a cultura?).

Este esquema foi testado inicialmente com três dissertações e foram feitos ajustes envolvendo uma equipe com cinco pessoas responsáveis pela coleta (duas pesquisadoras do grupo de pesquisa e três alunas bolsistas). Obtendo aprovação póstestagem, a fase seguinte foi destinada a leituras aprofundadas de cada uma das dissertações, sendo que todos os dados foram registrados em planilhas do Programa Excel. Cada informação registrada era então discutida coletivamente, a fim de que fossem resguardadas as interpretações, de modo mais próximo possível às informações construídas pelos próprios mestrandos, autores das dissertações. Ao longo do processo de coleta, esta equipe se reuniu regularmente para apresentar os dados obtidos, visando a uniformidade e veracidade das informações.

O processo analítico envolveu análise de conteúdo, ${ }^{15}$ procurando-se convergências e divergências entre as informações coletadas, levando em conta cada uma das dissertações analisadas. Foram executados os seguintes passos: construiuse, inicialmente, um referencial de codificação que se ajustava tanto às características da metodologia proposta na teoria de Leininger, quanto às dissertações em análise; a seguir, foi realizado um teste piloto, levantando dados de duas dissertações, verificando a fidedignidade e sensibilidade dos codificadores; e, posteriormente, passou-se então a codificar os materiais da amostra, comparando-os com o Modelo do Sol Nascente (Sunrise Model). ${ }^{6-7}$

Esta pesquisa foi desenvolvida nos termos da Resolução No 196/06 e suas complementares e da Resolução 251/97 e 292/ 99 do Conselho Nacional de Saúde, tendo seu projeto aprovado junto ao Comitê de Ética da UFSC sob o No 169/06.

\section{RESULTADOS E DISCUSSÃO}

Em todas as dissertações que utilizaram a teoria de Leininger como referência, identificamos que a metodologia teve por orientação os passos do processo de cuidar em enfermagem, seja na sua totalidade (contemplando as fases de levantamento de dados, diagnóstico, planejamento, implementação e avaliação), ou organizando-se em torno de algumas dessas etapas, em variadas combinações.

É relevante destacar que Leininger não utiliza esta terminologia em sua teoria, referindo-se à metodologia assistencial como uma prática humanística e participativa em direção à obtenção de cuidados culturalmente congruentes. ${ }^{6}$ Ao invés de processo de enfermagem ou processo de cuidar, a autora propõe o Modelo do Sol Nascente (Sunrise Model) como um caminho que dá baliza ao cuidado cultural em que a enfermeira começa com um domínio de interesse e, então, criativamente, passa a descobrir o melhor caminho para desenvolver a prática profissional. Ela refere que a metodologia para este cuidado deve ser um verdadeiro processo criativo que tem como desafio a sistematização 
do conhecimento e a tentativa contínua e dinâmica de aliar teoria e prática. Em suas próprias palavras, sua contribuição é a de propor "uma teoria para guiar a prática". 6:16

Diante do estímulo provocado pela obra de Leininger, os mestrandos optaram por propostas metodológicas bastante flexíveis e criativas. Todos declaram que as metodologias foram desenvolvidas com a participação ativa dos sujeitos (indivíduos, famílias, grupos, comunidades), através do diálogo reflexivo. Dos estudos sob investigação, apenas seis $(23,07 \%)$ declaram utilizar o Modelo do Sol Nascente como metodologia, reforçando que procuraram classificar e inter-relacionar os fatos, fenômenos e dados obtidos de acordo com os fatores que compõem a estrutura social e a visão de mundo dos sujeitos participantes. A utilização do processo de enfermagem como metodologia de estudo foi declarada em $15(57,69 \%)$ estudos e cinco $(19,23 \%)$ não explicitam a metodologia adotada ou registram-na de modo impreciso, ou ainda de difícil compreensão. A imensa maioria, portanto, realiza a trajetória metodológica sob os trilhos das etapas do processo assistencial de enfermagem.

Quanto à denominação utilizada para a metodologia dos estudos que adotam as etapas do processo assistencial de enfermagem ou as fases do Modelo do Sol Nascente, os autores exercitam o processo criativo e a nomeiam com uma ampla variedade de termos, como por exemplo: "processo de caminhar juntos", "prática de cuidar", "prática assistencial", "encontros assistenciais" ou simplesmente "processo de enfermagem". Um dado que chama a atenção é que a grande maioria não define o que entende por estes termos/processos utilizados, gerando dúvidas quanto à finalidade dos mesmos em relação aos objetivos propostos nas dissertações. Tal lacuna também fragiliza a tentativa de interpretação da coerência operacional das dissertações. Quanto às etapas constituintes das metodologias assistenciais adotadas pelas 21 dissertações, cujos processos cuidativos estão explícitos e claramente registrados, observamos que nem todas abordam as cinco fases clássicas do processo de enfermagem apontadas anteriormente.

Em geral, parece mesmo que os mestrandos escolhem a teoria antropológica de Leininger porque rejeitam, em algum grau, o processo de enfermagem tal como pensado e desenvolvido nos moldes clássicos, justificando, assim, que "o processo de enfermagem é uma metodologia positivista, rotineira e mecanizada e contrária aos princípios de uma filosofia humanística, holística ou fenomenológica". 16:35 Da maneira como os mestrandos constroem suas metodologias, ao focalizar comportamentos e hábitos culturais no caso de cuidar, certamente reafirma o pensamento crítico, quando exterioriza o sentimento de que essa teoria de cuidado é "a mais bem elaborada na enfermagem [...], já que o enfoque cultural significa e demonstra os comportamentos de cuidar em diferentes culturas, os quais correspondem, em última análise, ao modo de ser de cada um". 16:31

No que se refere à etapa da coleta de dados, dá-se ênfase à avaliação culturológica sugerida por Leininger, visando à avaliação sistemática dos significados e das práticas cuidativas dos indivíduos, famílias, grupos ou comunidades para determinar as necessidades do cuidado cultural, não apenas no momento inicial do processo, mas no decorrer do mesmo.

As técnicas ou guias habilitadores mais frequentemente utilizados para fazer a avaliação culturológica são, em primeiro lugar, a entrevista e a observação, sendo que esta última é classificada como "sistemática", "participante", ou ainda, como concebida por Leininger no Método O-P-R (Observation-Participation-Reflection) ${ }^{6-7}$ em que o enfermeiro primeiramente realiza observações e o escutar ativo mas não participa de forma completa e ampla, porém, com o decorrer das interações com os sujeitos do estudo, procede progressivamente a outros níveis mais ativos de atuação junto aos sujeitos, de modo que, ao final do processo, conquiste a obtenção de informações culturais, realizando principalmente reflexões sobre estes dados e reconfirmações concomitantes dos achados com os informantes. Além destas técnicas, os mestrandos também valem-se de conversas (ou encontros, ou reuniões) informais e de exame físico para auxiliar no procedimento de coleta de informações culturais, durante o processo saúde-doença.

As fontes de obtenção de dados são os próprios informantes (chave ou gerais, conforme os objetivos de cada estudo) e os prontuários ou documentos de identificação que ajudem na compreensão do status sócio-cultural da clientela. Como estratégias de contato com os sujeitos, os mestrandos optam por visitas domiciliares, técnicas ou dinâmicas de grupo (como as "oficinas", amplamente utilizadas neste tipo de operacionalização), interações promovidas em diversos ambientes por onde os sujeitos transitam durante o percurso terapêutico (como hospitais, ambulatórios, casas de saúde, maternidades, contatos com centros ou 
instituições religiosas e acesso a terapeutas do sistema informal de saúde, dentre outros) e, com menor frequência, o uso de narrativas terapêuticas e contatos telefônicos.

Um ponto positivo relevante que se observa quando se analisa a fase de avaliação culturológica é a grande profusão de instrumentos e técnicas cuidativas que são colocadas em movimento durante a coleta de informações sobre as práticas de saúde dos sujeitos e/ou grupos. A nosso ver, esta estratégia enriquece o mapa de dados e aproxima o enfermeiro da clientela, de modo mais confiável e seguro, além de proporcionar maior confiabilidade no desenvolvimento do rigor metodológico para proceder às etapas subsequentes do processo assistencial.

Por outro lado, observamos algumas fragilidades teórico-metodológicas durante a operacionalização desta importante etapa do processo, ligadas principalmente à forma com que os mestrandos interpretam ou concebem a "substância" que aparece impregnada nesses dados e que diz respeito, direta ou indiretamente, ao próprio significado do termo "cultura". Em alguns trabalhos, "o que" o mestrando vai buscar está íntima e somente ligado ao que é "exótico" ou fora do comum, como a prática popular de realização de massagens, com o intuito de livrar a criança da "arca-caída", ou então a "crença bizarra" de ingerir alimentos de coloração amarelada para livrar o indivíduo de "problemas de fígado". A cultura, nesta perspectiva, é interpretada como algo residual, irrelevante e, muitas vezes, como obstáculo a ser superado; ${ }^{17}$ uma interpretação que não se coaduna com a definição elaborada no contexto teórico do modelo de Leininger.

É possível que estas fragilidades sejam revertidas em outros propósitos mais benéficos do ponto de vista teórico-metodológico e do ponto de vista da qualidade da atenção em saúde, quando os mestrandos buscarem aprofundamentos na Antropologia da Saúde. Em nossa interpretação, para colocar em curso projetos profissionais e acadêmicos desta natureza - que visam produzir conhecimento, além de intervir na realidade prática da enfermagem - é indispensável uma imersão séria e sistemática na ciência antropológica. Por si só, embora relevante, não basta a tomada de consciência por parte dos enfermeiros de que os fatores e o contexto cultural são significativos na saúde e na doença; é imprescindível (re)conhecer-se que cultura é visão de mundo e merece ultrapassar a ideia de que são feixes de hábitos sem lógica que atrapalham o cuidado etic. Imergir nas fontes de onde Leininger extraiu suas premissas filosóficas para a concepção da Etnoenfermagem também pode ser útil no sentido de fortalecer as bases operacionais do cuidado cultural.

$\mathrm{Na}$ fase seguinte do processo assistencial, os mestrandos optam pela realização de leituras aprofundadas acerca dos dados levantados, interpretando o contexto em que tais informações foram coletadas, "verbalizadas" ou "observadas", buscando identificar então qual a(s) necessidade(s) de cuidado cultural a ser implementado, face aos requisitos atuais ou potenciais apresentados.

Percebemos que na ampla maioria das dissertações, esta etapa do processo assistencial não culmina com uma declaração diagnóstica. Antes disso, a reflexão sobre os dados obtidos serve como guia para indicar quais caminhos devem ser trilhados, a fim de chegar à obtenção (na maioria das vezes) conjunta de cuidados que sejam culturalmente congruentes. De forma geral, o processo analítico dessa fase de reflexão sistemática leva os autores a identificarem quais são as práticas e/ ou significados dessas práticas que precisam ser preservados, negociados ou repadronizados. A maioria é unânime em afirmar que nenhuma identificação é perene. Assim como os dados continuam sendo coletados nas demais fases do processo, também a identificação das práticas culturais pode ser provisória, e depois, ao aprofundar o trabalho, pode ser modificada, durante o desenrolar dinâmico das demais fases que o compõem.

Acreditamos que esta concepção diagnóstica é coerente com a proposta de Leininger, uma vez que a mesma é reiterativa em abordar que esta etapa não tem vida própria, não sendo, portanto, uma entidade separada da atividade processual; concepção que, do ponto de vista da teórica, é incompatível com qualquer espécie de taxonomia ou padronizações de linguagem diagnóstica.

Como contraponto, encontramos poucas dissertações que não concebem esta etapa como integrante da metodologia assistencial em enfermagem. Nestas dissertações, o levantamento de dados muitas vezes é bem amplo, generalizante e culturológicamente centrado, e a implementação ou a intervenção também é relatada, algumas vezes, de forma explícita e em concordância com o levantamento realizado nas várias fases do processo de cuidar. No entanto, e estranhamente, a fase de diagnóstico, ou seja, o ápice reflexivo para a tomada de decisões, está ausente, ou descrito de modo bastante superficial. 
Após o processo de identificação das necessidades culturais, os mestrandos apontam então para a próxima fase da sistematização da assistência de enfermagem, denominando-a como "plano de cuidados", "planejamento das ações com o cliente", "propondo caminhos para a ação conjunta" e demais denominações similares que, em síntese, caracteriza-se pela previsão das ações do enfermeiro e dos sujeitos participantes, de forma a conquistar padrões culturais que ultrapassem ou adéquem os requisitos culturais identificados nas fases antecessoras.

Pode-se dizer que, de modo quase unânime, os mestrandos utilizam-se das ações previstas nos componentes ou construtos do cuidar delineados por Leininger, dentre os 172 identificados pela teórica, em mais de 54 culturas ocidentais e orientais, como por exemplo: esclarecer, alertar, a poiar, acompanhar, desenvolver, dentre outros. Percebese que, na maioria das vezes, há preocupação dos mestrandos em individualizar os planos de ação, pautando-se na diversidade do cuidado cultural, conforme os pressupostos de Leininger. Observase também que esta fase de planejamento insere os sujeitos participantes como "pessoas em ação", 6:42 vale dizer, como pessoas, grupos ou comunidades que efetivamente participam das decisões no plano da assistência em saúde. Mais do que expectadores, os sujeitos são ativos no planejamento das ações e, em grande parte das dissertações, parecem possuir o direito de opinar a respeito de como gostariam que as ações acontecessem.

A fragilidade das dissertações, no que diz respeito à etapa do planejamento da assistência, relaciona-se com a postura da(o) enfermeira(o) com relação à maneira com que encara a mudança assistencial quando o que está em pauta é a sua cultura profissional e/ou da cultura institucional onde o cuidado de enfermagem ocorre. Assim, não é incomum encontrarem-se exemplos de planejamento em que o único agente a mudar a prática é o sujeito participante. São raras as ações em que o profissional olha para cultura da biomedicina com os olhos de estrangeiro, ${ }^{18-19}$ procurando mudar suas próprias atitudes, valores, conhecimentos ou significados para que sejam aceitas, evitando-se o etnocentrismo, e para que haja congruência com os valores e estilos de vida dos próprios clientes. O mesmo vale com relação à cultura organizacional; frequentemente as regras institucionais são "preservadas" e somente são "negociadas" ou "repadronizadas" as dos sujeitos participantes, o que revela, a nosso ver, o forte indício ainda pre- sente de que a cultura institucional e profissional tem valor maior que a "cultura" do cliente.

Este modo de intervir deveria revelar não apenas uma mudança nas ações que os sujeitos participantes necessitariam operar, mas também, indissociavelmente, deveriam provocar "transformações na própria enfermeira que, ao atuar, tem a oportunidade de rever seus conceitos, valores e crenças, às vezes tão profundamente enraizados em sua cultura profissional". 20:288 Também deveria intervir constantemente a fim de que as regras internas da instituição fossem flexibilizadas. Estes seriam planos de cuidado coerentes com a proposta anti-etnocêntrica de Leininger.

Quanto à fase de implementação ou de intervenção profissional, conforme apontamos anteriormente, as dissertações não são muito explícitas na sua descrição. Deste modo, em $60 \%$ delas os mestrandos relatam o modo como operacionalizaram o plano de cuidados e em $40 \%$ esta etapa é quase omissa. Quando a descrevem, trabalham com o significado de uma etapa que se caracteriza, quase sempre, como sendo a colocação em prática das ações vislumbradas na fase anterior que, como dissemos, é trabalhada em regime de cooperação com os sujeitos que estão envolvidos no processo assistencial.

A maioria das modalidades de ação colocada em prática envolve repadronização/reestruturação dos cuidados culturais, como por exemplo: os significados relacionados com o fato do bebê "pegar ar", a fim de que a família tirasse a criança de casa para realizar o "teste do pezinho" e iniciasse o esquema de vacinação na Unidade de Saúde; as práticas culturais em saúde que englobavam o uso de chás caseiros e de outras substâncias como "fel de galinha", fumo em corda, excreções de diversas origens; dentre outros. Nesta modalidade de planejamento, que envolve ações voltadas a repadronizações do cuidado cultural, os mestrandos atuam de modo bastante ativo. Promovem estímulos que permitem trabalhar com os significados impressos nas ações anteriormente levadas a cabo pelos sujeitos cuidados, com a finalidade de reduzir o agravo dos problemas de saúde, ou mesmo com a intenção de eliminar os sinais e sintomas associados aos quadros clínicos identificados por eles.

Como segunda modalidade de cuidado cultural, os mestrandos planejam ações declaradas como ações de acomodação/negociação. Os autores das dissertações, na sua grande maioria, não se preocupam em distinguir entre os con- 
ceitos de acomodação e negociação. De forma geral, adotam estes termos como sinônimos, e explicam a sua aplicação em situações nas quais o enfermeiro e o cliente entram com uma ação do cuidado. Como exemplo, o enfermeiro mantém o uso da faixa umbilical, respeitando o cuidado da família, mas orienta para utilizá-la de forma mais frouxa. Alguns autores demonstraram um outro entendimento de acomodação/negociação, exemplificando o fato de que o enfermeiro teve que se acomodar ao ambiente da família que, na avaliação do autor, era desconfortável.

Um dos autores chama atenção para o fato de que, nesta modalidade de relação com o cliente, o enfermeiro precisa alterar seus valores a respeito da prática profissional, para possibilitar a negociação/acomodação. Dois autores tiveram outro entendimento: o primeiro, que defendeu a dissertação ainda em 1990, considerou que a negociação é a base para fazer a preservação, acomodação e mesmo a repadronização dos cuidados; o segundo, cuja dissertação foi defendida em 2002, argumenta também que a negociação está sempre presente, e que, para acomodar um cuidado, o enfermeiro precisa negociar. Este autor, que realizou seu estudo em uma instituição privada, argumenta que os clientes são "exigentes" e "conscientes" de seus direitos, "obrigando" o enfermeiro a negociar. Tal interpretação se coaduna com publicação de resultado de outro estudo em que a autora, ${ }^{21}$ ao buscar compreender a percepção de alunos de mestrado e doutorado acerca das ações de negociar e acomodar, identificou que os mesmos não atribuem o mesmo sentido às duas ações. Chegou à conclusão que a enfermeira, ao interagir com os usuários nos cenários cuidativos, não negocia cuidados, e sim, acomoda-os às necessidades do sistema profissional.

A modalidade de planejamento menos frequente trata da ação de manutenção/ preservação de cuidado cultural. Embora os mestrandos insiram nos, planos assistenciais, ações como "manter a ingestão da dieta nos finais de semana", "apoiar a procura pela benzedeira como tratamento coadjuvante para a arca-caída”, "encaminhar a criança ao berçário da maternidade para que a mãe possa descansar" dentre outros, percebe-se que tais atividades não recebem a mesma ênfase adotada pelas duas modalidades descritas anteriormente. Esta nossa interpretação é coerente com aquela já descrita em momento anterior deste texto, quando insinuamos que os dados apontavam para uma fragilidade relacionada à persistência em "mudar" as condutas dos clientes, mas não refletiam perspectivas de mudanças dos valores da enfermeira ou da instituição. Isto talvez tenha alguma relação com certa desvalorização desta ação por parte dos enfermeiros, conforme outras publicações. ${ }^{17,20}$

Ainda que revelando certas fragilidades metodológicas, ao adotar as três modalidades de ações e decisões de Leininger, o que mais preocupa nestes trabalhos acadêmicos é o fato de que $40 \%$ deles são omissos no que diz respeito à etapa assistencial da operacionalização das ações planejadas, o que é um assunto de bastante relevância, visto que é na intervenção assistencial que se revelam as ações ou modos de atenção planejados na fase anterior.

Frequentemente, os autores relatam e refletem sobre os dados obtidos, as reflexões interpretativas que fizeram, o planejamento adotado para as diferentes perspectivas assistenciais e então passam a relatar e a avaliar os resultados parciais ou finais da (suposta) intervenção realizada sem, contudo, dizer como se deu a intervenção, a implementação do cuidado cultural. Dito de outra forma, em $40 \%$ destes estudos, faltam exemplos que permitam analisar se aquilo que foi planejado foi, efetivamente, colocado em prática, a fim de que se alcançasse o cuidado culturalmente congruente. Neste sentido, as probabilidades interpretativas para tal omissão são variadas, ainda que delimitemos as reflexões em torno da própria teoria de Leininger, que é nosso propósito precípuo. Talvez a própria teórica auxilie na interpretação ao sugerir que este modo "requer que a enfermeira possua profundo conhecimento da cultura e que faça uso criativo dele" $e^{\prime: 42}$

\section{CONCLUSÕES}

Ao final deste estudo, retomando seu objetivo, que foi o de analisar a operacionalização da metodologia assistencial nas dissertações de enfermagem elaboradas com base na Teoria de Leininger, pode-se considerar que já existe uma grande preocupação das enfermeiras colocando em foco o conceito de cultura para a prática de enfermagem, e buscando desenvolver metodologias que consideram apropriadas para definir operacionalmente as várias nuanças que compõem essa definição. Este fato pode ser considerado um avanço para a enfermagem brasileira, seja de modo direto, para a qualificação da prática assistencial, seja de modo indireto, para o incremento da própria produção de conhecimentos da Disciplina, na área cultural. 
A imensa maioria realiza a trajetória metodológica sob os trilhos das etapas do processo assistencial de enfermagem, tradicionalmente conhecido nos meandros profissionais. Diante do estímulo provocado pela obra de Leininger, contudo, os enfermeiros optam por propostas metodológicas bastante flexíveis e criativas. A fase de avaliação culturológica expõe uma profusão de instrumentos e técnicas cuidativas. Entretanto, a fase de diagnóstico, ou seja, o ápice reflexivo para a tomada de decisões, está ausente, ou descrito de modo superficial, o que se revela como uma das fragilidades destes estudos.

No que diz respeito, direta ou indiretamente, ao significado do termo "cultura", a utilização deste conceito está fortemente permeado pelo olhar do profissional de saúde e do senso comum. A consequência é que, em alguns trabalhos, "o que" o mestrando vai buscar permanece intimamente ligado ao que é "exótico", "primitivo", "extraordinário". Assim, a cultura é apenas a do outro, sem se dar conta da própria cultura e da cultura do subsistema profissional. Tal fragilidade é corroborada pelo fato de que os autores realizaram muito mais a repadronização e acomodação/negociação do que a preservação dos cuidados, o que mostra a dificuldade de se enxergarem como parte desta cultura, dificultando a reflexão sobre as perspectivas de mudanças dos valores da enfermeira ou da instituição.

Ainda com relação às fragilidades observadas, ao adotarem as três modalidades de ações e decisões de Leininger, o que mais preocupa nestes trabalhos acadêmicos é o fato de que muitos deles são omissos no que diz respeito à etapa assistencial da operacionalização das ações planejadas. Os autores não descrevem em detalhes como ocorreu a implementação do cuidado cultural, o que seria fundamental para a realização de outros estudos e, principalmente, para fornecer subsídios aos estudantes de enfermagem e enfermeiros que quisessem utilizar a mesma, na prática assistencial. Ressalta-se também que, deste modo, o próprio rigor teóricometodológico desses estudos fica comprometido.

A presente pesquisa fica limitada em seus contornos locais, uma vez que analisou trabalhos acadêmicos de um Programa particular de pósgraduação brasileiro - e requer, seguramente, o aprofundamento e maior abrangência de seu escopo, trazendo à tona outras realidades locais, regionais, ou mesmo nacionais - mas, por outro lado, os resultados revelam uma amostra fidedigna de que é importante continuar descobrindo e construindo requisitos e "modos de fazer" para que as enfermeiras possam realizar, cotidianamente, o cuidado culturalmente congruente, em qualquer cenário assistencial.

\section{REFERÊNCIAS}

1. Alligood MR. Philosophies, models, and theories: critical thinking structures. In: Alligood MR, Tomey AM. Nursing theory: utilization \& application. Missouri (US): Mosby; 2006. p. 43-65.

2. Chinn PL, Kramer MK. Theory and nursing: a systematic approach. $4^{\text {th }}$ ed. St Louis (US): MosbyYear Book; 1995.

3. Hermida PMV, Araújo IEM. Sistematização da assistência deenfermagem: subsídios para implantação. Rev Bras Enf. 2006 Set-Out; 59(5):675-9.

4. Silva VM, Oliveira C, Damasceno MMC, Araujo L. Linguagens da sistematização da assistência de enfermagem nas dissertações e teses dos catálogos do Centro de Estudo e Pesquisa em Enfermagem. Online Braz J Nurs [online]. 2006 [acesso 2008 Mar 06]; 5(2). Disponível em: http:/ / www.portalbvsenf.eerp. usp.br/scielo.php?script=sci_arttext\&pid=S167642852006000200021\&Ing=pt\&nrm=iso

5. Zuzelo PR, Gettis C, Hansell AW, Thomas L. Describing the influence of technologies on registered nurses' work. Clinical Nurse Specialist. 2008; 22(3):132-40.

6. Leininger M. Cultural care diversity and universality: a theory of nursing. New York: National League for Nursing Press; 1991.

7. Leininger MM, McFarland MR. Culture care diversity and universality: a worldwide nursing theory. New York (NY): McGraw-Hill; 2006.

8. Oriá MOB, Ximenes LB, Alves MDS. Madeleine Leininger and the theory of the Cultural Care Diversity and Universality: an historical overview. Online Braz J Nurs [online]. 2005 [acesso 2009 Jun 04]; 4(2). Disponível em: http:/ / www.uff.br/ nepae/objn402oriaetal.htm

9. Queiroz MVO, Pagliuca LMF. Conceito de enfermagem transcultural: análise de seu desenvolvimento em uma dissertação de mestrado. Rev Bras Enf. 2001 Out-Dez; 54(4):630-4.

10. Moura MAV, Chamilco RASI, Silva LR. A teoria transcultural e sua aplicação em algumas pesquisas de enfermagem: uma reflexão. Esc Anna Nery R Enferm. 2005 Dez; 9(3):434-40.

11. Silva ARV, Bezerra CP, Joça M, Alves MDS, Leitão GCM. O cuidado como marco conceitual para dissertações e teses de um programa de pós-graduação do nordeste. Online Braz J Nurs [online]. 2006 [acesso 2008 Mar 07]; 5(2). Disponível em: http://www.uff.br/objnursing/index.php/ nursing/issue/view/3 
12. Oriá MOB, Ximenes LB, Alves MDS. Utilização da teoria do cuidado cultural na pós-graduação em enfermagem: a realidade brasileira. Rev Enferm UERJ. 2006 Abr-Jun; 14(2):245-52.

13. Monticelli M, Boehs AE, Guesser JC, Gehrmann T, Paiva K. Perfil de dissertações que utilizam a Teoria de Leininger vinculadas a um programa de mestrado em enfermagem do sul do país. Cienc Cuid Saúde. 2008 Out-Dez; 7(4):439-46.

14. Trentini M, Paim L. Pesquisa convergente-assistencial. $2^{\mathrm{a}}$ ed. Florianópolis (SC): Insular; 2004.

15. Bauer MV. Análise de conteúdo clássica. In: Bauer M, Gastel G. Pesquisa qualitativa com contexto, imagem e som: um manual prático. $4^{\mathrm{a}}$ ed. Petrópolis (RJ): Vozes; 2004.

16. Waldow VR. O cuidado na saúde: as relações entre o eu, o outro e o cosmos. Petrópolis (RJ): Vozes; 2004.
17. Monticelli M, Elsen I. A cultura como obstáculo: percepções da enfermagem no cuidado às famílias em alojamento conjunto. Texto Contexto Enferm. 2006 Jan-Mar; 15(1):26-34.

18. Geertz C. Nova luz sobre a antropologia. Rio de Janeiro (RJ): Jorge Zahar; 2001.

19. Becker SG, Rosa LM, Manfrini GC, Backes MTS, Meirelles BHS, Santos SMA. Dialogando sobre o processo saúde/doença com a Antropologia: entrevista com Esther Jean Langdon. Rev Bras Enf. 2009 Mar-Abr; 62(2):323-6.

20. Monticelli M. Nascimento como um rito de passagem: abordagem cultural para o cuidado às mulheres $\mathrm{e}$ recém-nascidos. São Paulo (SP): Robe; 1997.

21. Boehs AE. Análise dos conceitos de negociação/ acomodação da teoria de Madeleine Leininger. Rev Latino-am Enfermagem. 2002 Jan; 10(1):90-6. 